\title{
Supply and Demand: Association Between Non-English Language-Speaking First Year Resident Physicians and Areas of Need in the USA
}

\author{
Lisa C. Diamond, MD, MPH ${ }^{1,2}$ (D) Imran Mujawar, MBBS, $M S^{7}$, Erik Vickstrom, $P D^{3,4}$, \\ Margaux Genoff Garzon, $M A^{5}$, and Francesca Gany, MD, $M S^{1,2}$
}

${ }^{1}$ Memorial Sloan Kettering Cancer Center New York, NY, USA; ${ }^{2}$ Weill Cornell Medicine New York, NY, USA; ${ }^{3}$ United States Census Bureau Suitland, MA, USA; ${ }^{4}$ IZA Institute of Labor Economics Bonn, Germany; ${ }^{5}$ The New School for Social Research New York, NY, USA.

BACKGROUND: Over 25 million US inhabitants are limited English proficient (LEP). It is unknown whether physicians fluent in non-English languages are training in geographic areas with the highest proportion of LEP people. Diversity of language ability in the physician workforce is an important complement to language assistance services for providing quality care to LEP patients.

OBJECTIVE: To determine whether non-English language-speaking resident physicians matched in the geographic areas where language skills are needed.

DESIGN: Cross-sectional study.

PARTICIPANTS: Postgraduate medical training applicants to the Association of American Medical College's Electronic Residency Application Service in 2013-2014 $(n=50,766)$. We included data from the Graduate Medical Education Track database, mapped against American Community Survey data.

INTERVENTIONS: N/A.

MAIN MEASURES: We assessed the geographic alignment of non-English language-speaking resident physicians relative to the distribution of the LEP-speaking population.

KEY RESULTS: While 37\% of resident physicians spoke at least one non-English language, in most cases the languages they spoke were not those in greatest need by the US LEP population. LEP speakers' potential exposure to non-English language-speaking residents varied. For Spanish, the language with the lowest national resident physician to Spanish LEP patient ratio, the ratio was most favorable in New York at 23.7/100,000 LEP population versus 5.1 in Los Angeles. For Tagalog, the group with the highest geographic mismatch, the ratio was 70.4 in New York but 0 in San Diego, San Jose, and Seattle. Among the top five LEP languages in the USA, Chinese-speaking resident physicians were the most geographically matched.

CONCLUSIONS: We found considerable misalignment of the geographic distribution of non-English language-

Prior Presentations These data were presented at the Society of General Internal Medicine Annual Meeting on April 19, 2017, in Washington, DC.

Electronic supplementary material The online version of this article (https://doi.org/10.1007/s11606-020-05935-7) contains supplementary material, which is available to authorized users.

Received August 5, 2019

Accepted May 18, 2020

Published online June 2, 2020 speaking resident physicians relative to the distribution of the LEP-speaking population. Residency programs in areas of high need could consider better matching the non-English language needs of their community with the language abilities of the resident physicians they are recruiting.

KEY WORDS: language barriers; physician workforce; physician-patient communication; health disparities; graduate medical education.

J Gen Intern Med 35(8):2289-95

DOI: $10.1007 / \mathrm{s} 11606-020-05935-7$

(c) Society of General Internal Medicine 2020

\section{BACKGROUND}

Over 25 million people in the USA are limited English proficient (LEP), ${ }^{1}$ representing an increase of $80 \%$ from 1990 to $2010 .^{2}$ LEP patients have difficulty reading, writing, and understanding English, which leads to difficulty functioning in the English language-dominant healthcare system. ${ }^{3}$ Due to language barriers, LEP patients tend to have more negative experiences in the medical system. ${ }^{4-7}$ LEP patients have fewer encounters with clinicians ${ }^{8}$ and are less satisfied with their care than English-speaking patients. ${ }^{6}$ LEP patients are more likely to have costly diagnostic tests, ${ }^{5}$ be misdiagnosed, ${ }^{9}$ and have poor or incomplete treatment plans. ${ }^{5}$ For LEP patients, truly bilingual providers can improve care ${ }^{10}$ by increasing LEP patients' understanding of their care, ${ }^{11}$ being more responsive to their concerns, ${ }^{12}$ and improving their participation in and recall of health conversations. ${ }^{13}$

Resident physicians are often the front line of both inpatient and outpatient care for underserved patients, many of whom are LEP. ${ }^{14}$ We previously showed that at the national level, the language diversity of the resident physician workforce does not match the languages spoken by the US LEP population. Among new MDs who entered residency in 2013, there is a relative underrepresentation of resident physicians with language fluency in $4 / 5$ of the most commonly spoken nonEnglish languages in the USA: Spanish, Vietnamese, Korean, and Tagalog. ${ }^{15}$ That is, among the national pool of resident physicians, the proportion who speaks Spanish, Vietnamese, Korean, and Tagalog is lower than the proportion of the 
resident physicians who reported at least advanced proficiency in any non-English language. It is unknown whether resident physicians fluent in non-English languages are training in the geographic areas with the highest concentrations of LEP patients. This has postresidency training implications as well. Almost half (47.2\%) of physicians practice in the state where they completed their residency. California and Texas are states with both high rates of retention after residency completion $(62.7 \% \text { and } 59.7 \% \text { respectively })^{16}$ and a high proportion of LEP patients (44.4\% and $41.9 \%$, respectively). ${ }^{17}$ Thus, it is important to study language proficiency among resident physicians in order to get a sense of the future physician workforce in a given geographic area.

The objective of this study was to assess the geographic areas in which resident physicians fluent in non-English languages are serving in US residency programs compared to the geographic areas where these language skills are most needed.

\section{DATA AND METHODS}

This study focuses on geographic location and language aptitude for all (both USA and foreign educated) 2013 and 2014 first year resident physicians in the 50 states of the USA and in Washington, DC $(n=50,766)$. Data on language aptitude is taken from the AAMC Electronic Residency Application Service (ERAS) database. ERAS is an online application service which transmits applications and other supporting documents to residency programs. The applicants are asked to self-report their language skills with an adapted Interagency Language Roundtable (ILR) scale with five response options and detailed descriptors: "native/functionally native," "advanced," "good," "fair," and "basic." The AAMC began using the ILR scale in 2013 to standardize the way applicants selfreported their language skills. The ILR scale was developed in the 1950s and has become a standardized self-reporting scale for speaking, listening, writing, and translating skills. Since its inception, the scale has been revised and validated and has been used extensively in academia, government, and non-governmental organizations. ${ }^{18}$ It is increasingly being used as a self-reporting tool for clinicians. ${ }^{19-22}$ Data on geographic location of the residency program is taken from the Graduate Medical Education Track (GMETrack) database. These resident physicians applied for postgraduate training by registering once with ERAS in a given year and having their application sent to the residency programs to which they wished to apply. The application includes socio-demographic questions, such as racial/ethnic identity and languages spoken. Applicants were asked to self-report language proficiency in all languages spoken, including English.

This study assigned the residency program location to Core Based Statistical Area (CBSA) IDs using the physical addresses of residency programs obtained from GMETrack. The program locations were assigned to 238 metropolitan CBSAs (of which there were 381 with populations of 50,000 or more) and 25 were assigned to micropolitan CBSAs (of which there were 536 with populations between 10,000 and 49,999). This study focused on the 238 metropolitan areas with residency programs. Then, using the 2009-2013 American Community Survey (ACS) data, we attached population data for LEP-speaking persons to these metropolitan areas. This study focused on the five most common languages spoken by LEP people in the USA - Spanish, Chinese (Mandarin, Cantonese, and others combined), Vietnamese, Korean, and Tagalog. The US Census Bureau categorizes individuals as LEP if they report speaking English less than "very well."

\section{Estimating LEP Speakers' Potential Exposure to Non-English Language-Speaking Resident Physicians}

We first calculated for the national level and for each metropolitan area with a residency program the number of first year resident physicians who reported speaking a non-English language with at least "advanced" proficiency for every 100,000 LEP speakers of that language. Because our analytical focus was on first year resident physicians and we had 2 years of data for incoming resident physicians (2013 and 2014), we divided the ratios by 2 . The ratio enables us to compare relative representation of resident physicians to LEP speakers by language and by geographic unit.

We conducted analyses in STATA 12 (College Station, TX).

\section{RESULTS}

The 238 metropolitan areas with residency programs account for $77 \%$ of the US population aged 5 or older and $90 \%$ of the population residing in metropolitan areas (Supplemental Appendix Table 1). In the metropolitan areas with residency programs, there were 11.3 first year resident physicians for every 100,000 people. We found that $36.5 \%$ (18,373 of 50,303 ) of resident physicians in 2013 and 2014 spoke at least one non-English language with at least advanced proficiency. On the other hand, $10 \%$ of the population $(22,472,727$ of $224,012,869)$ was LEP. Of these resident physicians, 39\% spoke one of the top five languages used in the USA with the most common being Spanish (24\%).

Therefore, there was a higher ratio of non-English language-proficient resident physicians per 100,000 LEP population at the national level (36.9, Table 1) compared with the overall population (11.3, Supplemental Appendix Table 1). There was a preponderance of languages spoken by resident physicians including Hindi and Urdu that were not the five most common non-English languages spoken in the USA. ${ }^{15}$ LEP speakers' exposure to non-English language-speaking resident physicians differed drastically by language. Nationally, the resident physician to LEP ratio was least favorable for Spanish at 13.6. Among the Asian languages, ratios were also lower for Tagalog at 20.2 and 22.7 for Vietnamese while 
Table 1 LEP Population and Resident Physicians with Advanced Fluency in a Non-English Language by CBSA

\begin{tabular}{|c|c|c|c|}
\hline Metropolitan area & $\begin{array}{l}\text { Population LEP in } \\
\text { CBSA }\end{array}$ & $\begin{array}{l}\text { No. of resident physicians with at least } \\
\text { "advanced" fluency }(\%)\end{array}$ & $\begin{array}{l}\text { Ratio: resident physicians } \\
\text { per } 100,000^{\mathrm{a}}\end{array}$ \\
\hline \multicolumn{4}{|l|}{ Total limited English proficient (LEP) } \\
\hline $\begin{array}{l}\text { New York-Newark-Jersey City, } \\
\text { NY-NJ-PA }\end{array}$ & $3,148,722$ & $4006(55.7)$ & 63.6 \\
\hline Los Angeles-Long & $3,021,722$ & $670(39.2)$ & 11.1 \\
\hline \multicolumn{4}{|l|}{ Beach-Anaheim, CA } \\
\hline Miami-Fort Lauderdale-West Palm & $1,246,298$ & $321(57.0)$ & 12.9 \\
\hline \multicolumn{4}{|l|}{ Beach, FL } \\
\hline Chicago-Naperville-Elgin, IL-IN-WI & $1,077,695$ & 1009 (41.9) & 46.8 \\
\hline Houston-The & 947,943 & $465(38.7)$ & 24.6 \\
\hline \multicolumn{4}{|l|}{ Woodlands-Sugar Land, TX } \\
\hline Dallas-Fort Worth-Arlington, TX & 805,047 & $206(28.9)$ & 12.8 \\
\hline San Francisco-Oakland-Hayward, CA & 736,524 & $261(33.0)$ & 17.7 \\
\hline Riverside-San & 640,984 & $194(48.7)$ & 15.2 \\
\hline \multicolumn{4}{|l|}{ Bernardino-Ontario, CA } \\
\hline Washington-Arlington-Alexandria, & 541,111 & $364(41.3)$ & 33.7 \\
\hline \multicolumn{4}{|l|}{ DC-VA-MD-WV } \\
\hline San Diego-Carlsbad, CA & 476,405 & $128(39.1)$ & 13.5 \\
\hline \multicolumn{4}{|l|}{ Spanish LEP } \\
\hline \multirow{2}{*}{\multicolumn{4}{|c|}{ Beach-Anaheim, CA }} \\
\hline & & & \\
\hline New York-Newark-Jersey City, & $1,675,204$ & $792(11.0)$ & 23.7 \\
\hline NY-NJ-PA & & & \\
\hline Miami-Fort Lauderdale-West Palm & $1,004,653$ & $204(36.2)$ & 10.2 \\
\hline \multicolumn{4}{|l|}{ Beach, FL } \\
\hline Houston-The & 769,535 & $154(12.8)$ & 10.0 \\
\hline \multicolumn{4}{|l|}{ Woodlands-Sugar Land, TX } \\
\hline Chicago-Naperville-Elgin, IL-IN-WI & 679,023 & $245(10.2)$ & 18.1 \\
\hline Dallas-Fort Worth-Arlington, TX & 645,031 & $67(9.4)$ & 5.2 \\
\hline Riverside-San & 533,544 & $54(13.6)$ & 5.1 \\
\hline \multicolumn{4}{|l|}{ Bernardino-Ontario, CA } \\
\hline San Diego-Carlsbad, CA Metro Area & 319,880 & $44(13.5)$ & 6.9 \\
\hline San Francisco-Oakland-Hayward, CA & 310,669 & $110(13.9)$ & 17.7 \\
\hline Phoenix-Mesa-Scottsdale, AZZ & 307,781 & $35(7.7)$ & 5.7 \\
\hline \multicolumn{4}{|l|}{ Chinese LEP } \\
\hline New York-Newark-Jersey City, & 364,299 & $370(5.1)$ & 50.8 \\
\hline \multicolumn{4}{|l|}{ NY-NJ-PA } \\
\hline Los Angeles-Long & 239,576 & $126(7.4)$ & 26.3 \\
\hline \multicolumn{4}{|l|}{ Beach-Anaheim, CA } \\
\hline San Francisco-Oakland-Hayward, CA & 203,434 & $37(4.7)$ & 9.1 \\
\hline San Jose-Sunnyvale-Santa Clara, CA & 61,687 & $34(10.9)$ & 27.6 \\
\hline Boston-Cambridge-Newton, MA-NH & 51,325 & $85(5.2)$ & 82.8 \\
\hline Chicago-Naperville-Elgin, IL-IN-WI & 44,600 & $83(3.4)$ & 93.1 \\
\hline Seattle-Tacoma-Bellevue, WA & 36,399 & $18(2.5)$ & 24.8 \\
\hline Washington-Arlington-Alexandria, & 35,954 & $25(2.8)$ & 34.8 \\
\hline \multicolumn{4}{|l|}{ DC-VA-MD-WV } \\
\hline Philadelphia-Camden-Wilmington, & 33,585 & $66(3.4)$ & 98.3 \\
\hline PA-NJ-DE-MD & & & \\
\hline Houston-The & 32,227 & $47(3.9)$ & 72.9 \\
\hline \multicolumn{4}{|l|}{ Woodlands-Sugar Land, TX } \\
\hline Vietnamese LEP & & & \\
\hline Los Angeles-Long & 147,472 & $43(2.5)$ & 14.6 \\
\hline Beach-Anaheim, CA & & & \\
\hline San Jose-Sunnyvale-Santa Clara, CA & 69,212 & $5(1.6)$ & 3.6 \\
\hline Houston-The & 55,203 & $20(1.7)$ & 18.1 \\
\hline Woodlands-Sugar Land, TX & & & \\
\hline Dallas-Fort Worth-Arlington, TX & 39,230 & $14(2.0)$ & 17.9 \\
\hline Washington-Arlington-Alexandria, & 29,164 & $7(0.8)$ & 12.0 \\
\hline DC-VA-MD-WV & & & \\
\hline Seattle-Tacoma-Bellevue, WA & 28,629 & $5(0.7)$ & 8.8 \\
\hline San Francisco-Oakland-Hayward, CA & 26,667 & $13(1.6)$ & 24.4 \\
\hline San Diego-Carlsbad, CA Metro Area & 26,076 & $5(1.5)$ & 9.6 \\
\hline Atlanta-Sandy Springs-Roswell, GA & 21,665 & $3(0.8)$ & 6.9 \\
\hline $\begin{array}{l}\text { Philadelphia-Camden-Wilmington, } \\
\text { PA-NJ-DE-MD }\end{array}$ & 19,385 & $9(0.5)$ & 23.2 \\
\hline
\end{tabular}

\begin{tabular}{|c|c|c|c|}
\hline \multicolumn{4}{|l|}{$\overline{\overline{\text { Korean LEP }}}$} \\
\hline Los Angeles-Long Beach-Anaheim, CA & 156,343 & $33(1.9)$ & 10.6 \\
\hline New York-Newark-Jersey City, NY-NJ-PA & 93,503 & $94(1.3)$ & 50.3 \\
\hline Washington-Arlington-Alexandria, DC-VA-MD-WV & 33.611 & $10(1.1)$ & 14.9 \\
\hline Chicago-Naperville-Elgin, IL-IN-WI & 23,998 & $26(1.1)$ & 54.2 \\
\hline Seattle-Tacoma-Bellevue, WA & 23,035 & $8(1.1)$ & 17.4 \\
\hline Atlanta-Sandy Springs-Roswell, GA & 21,996 & $3(.8)$ & 6.8 \\
\hline
\end{tabular}


Table 1. (continued)

\begin{tabular}{|c|c|c|c|}
\hline San Francisco-Oakland-Hayward, CA & 16,910 & $6(.8)$ & $\overline{17.8}$ \\
\hline Dallas-Fort Worth-Arlington, TX & 14,821 & $9(1.3)$ & 30.4 \\
\hline Philadelphia-Camden-Wilmington, PA-NJ-DE-MD & 14,394 & $20(1.0)$ & 69.5 \\
\hline San Jose-Sunnyvale-Santa Clara, CA & 12,494 & $4(1.3)$ & 16.0 \\
\hline \multicolumn{4}{|l|}{ Tagalog LEP } \\
\hline Los Angeles-Long Beach-Anaheim, CA & 86,691 & $11(0.6)$ & 6.4 \\
\hline San Francisco-Oakland-Hayward, CA & 53,027 & $3(0.4)$ & 2.9 \\
\hline New York-Newark-Jersey City, NY-NJ-PA & 39,069 & $55(0.8)$ & 70.4 \\
\hline San Diego-Carlsbad, CA & 35,580 & $0(0.0)$ & 0.0 \\
\hline Urban Honolulu, HI & 23,282 & $1(0.6)$ & 2.2 \\
\hline Chicago-Naperville-Elgin, IL-IN-WI & 21,731 & $17(0.7)$ & 39.1 \\
\hline San Jose-Sunnyvale-Santa Clara, CA & 19,949 & $0(0.0)$ & 0.0 \\
\hline Las Vegas-Henderson-Paradise, NV & 18,628 & $3(2.0)$ & 8.1 \\
\hline Riverside-San Bernardino-Ontario, CA & 16,986 & $6(1.5)$ & 17.7 \\
\hline Seattle-Tacoma-Bellevue, WA & 13,851 & $0(0.0)$ & 0.0 \\
\hline
\end{tabular}

Data are drawn from the 2009-2013 American Community Survey 5-Year Estimates. American FactFinder: US Census Bureau; U.S. Census Bureau 2011 and the Association of American Medical College Electronic Residency Application Service and GMETrack databases

${ }^{a}$ Ratio was divided by 2 to represent 1 year of first year resident physicians

higher for Korean at 38.5 and 52.9 for Chinese (Supplemental Appendix Table2).

Table 1 shows the resident physician to LEP ratios for the 10 CBSAs with the most LEP speakers for all LEP nonEnglish language speakers. In addition to Spanish having the least favorable ratio, there were considerable regional variations. For example, the resident physician to Spanish LEP ratio was highest in New York at 23.7 but only 5.1 in Los Angeles. The misalignment was even greater for Asian languages. For Chinese (1686 resident physicians), the resident physician to Chinese LEP ratio was 98.3 in Philadelphia and 50.8 in New York but just 9.1 in San Francisco. The differences were most drastic for Tagalog (207 resident physicians), in which the resident to LEP ratio was 70.4 in New York and 39.1 in Chicago, but just 2.9 in San Francisco, and zero in San Diego, San Jose, and Seattle. These results suggest that the resident physician population proficient in particular non-English languages is not evenly distributed across metropolitan areas.

\section{DISCUSSION}

This study demonstrates that within the USA, in 2013 and 2014, the geographic distribution of first year resident physicians that spoke non-English languages did not align with the geographic distribution of the general LEP population. We found that while a third of first year resident physicians reported fluency in non-English languages, in most cases, the languages they were fluent in were not those in greatest need by the US LEP population. We further demonstrated that the geographic distribution of the first year resident physicians who do speak the languages of greatest needs did not align with the distribution of the LEP population. That is, the resident physicians reporting linguistic proficiencies did not always train in the localities in which these abilities can be deployed for the greatest numbers who could benefit. Areas with larger numbers of medical centers (e.g., the Northeast) had higher ratios of language-concordant resident physicians to LEP population when compared with metropolitan areas with smaller numbers of teaching hospitals (e.g., the Southern border). Similarly, there appears to be an inverse relationship with the level of language diversity in an area and ratio of resident physicians to LEP population. For example, in Chicago, where LEP patients were primarily Spanish and Polish speaking, there was a higher ratio of resident physicians to LEP patient population compared to areas like Southern California, where there is a greater diversity of languages spoken, including Korean, Tagalog, Armenian, and Persian. ${ }^{1}$

Studies have shown that language concordance between patients and bilingual physicians results in improved healthcare quality and outcomes. Language concordance between patients and physicians leads to better patient satisfaction with care, ${ }^{23,}{ }^{24}$ medication adherence, ${ }^{25,}{ }^{26}$ patient understanding of diagnoses and treatment, ${ }^{27}$ patient functioning for LEP patients with diabetes, ${ }^{28}$ patient centeredness, ${ }^{12}$ and more health education. ${ }^{24,}{ }^{29}$ Having a language-concordant physician leads to fewer emergency department visits, less likelihood of missing medications, and lower cost. ${ }^{25,} 30,{ }^{31}$ While language-concordant physicians can improve healthcare outcomes, they are only one intervention that can be utilized to improve LEP patient care. Trained medical interpreters are crucial components to improving healthcare outcomes for LEP patients, ${ }^{32,33}$ yet research suggests that that they are underused by physicians, even when readily available. ${ }^{21,} 27$, 34-37 While it is important to foster clinician's non-English language skills, it is equally as imperative to train new physicians on how to use language services.

There are federal regulations which require healthcare organizations to provide language services to LEP patients which includes the Title VI of the Civil Rights Act and was later reinforced by Executive Order 13166, which required that all recipients of federal funds provide "meaningful access" to services needed by people with LEP. The Culturally and Linguistically Appropriate Services standards (CLAS standards) in Health Care, issued by the Department of Health and Human Services' Office of Minority Health, include four that outline 
what it means to provide adequate language services to LEP patients as proscribed in Title VI. ${ }^{38}$ These four CLAS standards are requirements for all recipients of Federal funds. Medical students should be taught early in their education on these mandates and how to properly utilize language services. Research has shown that only a small percentage of medical students feel prepared to work with LEP populations and knowledge around interpreter use is a crucial component of their preparedness. ${ }^{39,}{ }^{40}$ Currently, not all residency programs provide training on caring for LEP patients nor do they have adequate tools to evaluate their resident physicians' abilities to provide care to this population. ${ }^{41}$ Providing comprehensive language services, educating future physicians on using professional interpreters, and increasing the number of resident physicians fluent in the languages commonly spoken by LEP patients at a particular residency program are important ways of complying with the CLAS standards and have the potential to reduce the geographic mismatch observed in this study.

Although the population of LEP is growing in the USA, the racial, ethnic, and linguistic diversity of the physician workforce is not changing as quickly, leading to predicted shortages in meeting the needs of LEP patients. ${ }^{42}$ Albeit, it cannot be expected that physicians will choose their place of work solely on their non-English language capabilities. It is up to sites to make their training programs attractive to diverse resident physician candidates. The AAMC's recent report entitled "Optimizing Graduate Medical Education: A Five-Year Road Map for America's Medical Schools, Teaching Hospitals and Health Systems" includes aligning residency training positions with societal needs as a priority. ${ }^{43}$ The federal government has established incentive programs to decrease shortages and improve recruitment and retention of physicians in underserved areas. ${ }^{44,}{ }^{45}$ Studies have also investigated how to improve the geographic distribution of physicians in rural and underserved areas. ${ }^{46,47}$ The exact number of physicians that are needed per language in each specialty is currently unknown and beyond the scope of this research. Our study could guide residency programs with high percentages of LEP patients to alter the way they recruit non-English languagespeaking resident physicians. As programs look to recruit resident physicians with diverse language skills, future studies are needed to determine the association between patientresident physician language concordance and healthcare outcomes for LEP patients.

Our study has limitations. First, our findings focus on language concordance between first year resident physicians and LEP patients. Care in these systems likely includes (a) faculty who may, themselves, have language fluency and who are supervising care, (b) professional interpreter services, and (c) resident physician education about effectively communicating with LEP patients. Second, the non-English language skills of resident physicians further along in their training who matched in prior years are not reflected in our analysis. We are assuming that the proportions of non-English languageproficient resident physicians do not vary widely from year to year. Additionally, many resident physicians tend to stay and practice in the state of their residency training, so studying these first cohorts of resident physicians for which we have language proficiency data will likely reflect the language diversity in the future workforce of those areas. ${ }^{48}$ Third, the resident physicians' language proficiencies are based on selfreport. However, we focused on resident physicians who reported at least advanced proficiency on the adapted ILR scale, which has been shown to be accurate compared to a validated oral proficiency interview in a previous study. ${ }^{22}$ Fourth, this study looks at aggregate numbers of non-English language-proficient resident physicians in a particular geographic area, and even if more language-concordant physicians were available, this does not guarantee that an LEP patient would end up being treated by one. Similarly, it would have been interesting to report where Latino Spanish-speakers were in training, but due to having only aggregate data, we were unable to link race/ethnicity of individual applicants with their language data. Furthermore, medical interactions occur at the clinic and hospital level. Our data is not granular enough to evaluate these interactions. Fifth, given the nature of our data, we had no measure of care-seeking behavior and, thus, cannot measure whether there is a demand being unmet due to the observed geographic misalignment of LEP people and nonEnglish-speaking resident physicians. Finally, our study grouped resident physicians going into any specialty together for this analysis. There may be important differences in the need for fluent primary care physicians vs. specialist physicians.

\section{CONCLUSIONS}

Diversity of language ability in the physician workforce is an important complement to language assistance services for providing quality care to patients with LEP. Residency programs should be aware of the needs of their LEP communities and continuously monitor the languages in their geographic area to identify these needs. Residency programs in areas of high need should consider the extent to which recruiting resident physicians with non-English language fluencies would improve the service to their communities. Future research should focus on the relationship between geographic mismatch of non-English language-fluent resident physicians and quality of care and outcomes for LEP patients.

Acknowledgments: The authors wish to acknowledge the contributions of Douglas Grbic, PhD, and Imam Xierali, PhD, of the Association of American Medical Colleges, and Emory Morrison, PhD.

Corresponding Author: Lisa C. Diamond, MD, MPH; Memorial Sloan Kettering Cancer Center New York, NY, USA (e-mail: diamondl@mskcc.org).

Funding Information Dr. Diamond was supported by Memorial Sloan Kettering Cancer Center Support Grant/Core Grant (P3O CA008748) and NCI KO7 CA184037. 


\section{Compliance with Ethical Standards:}

Conflict of Interest: The authors declare that they do not have a conflict of interest.

Disclaimer: Design and conduct of the study; collection, management, analysis, and interpretation of the data; preparation, review, or approval of the manuscript; and decision to submit the manuscript for publication were independent of both Memorial Sloan Kettering Cancer Center and the Association of American Medical Colleges. Dr. Diamond had full access to all of the data in the study and takes responsibility for the integrity of the data and the accuracy of the data analysis. Any views expressed are those of the authors and not necessarily those of the US Census Bureau.

\section{REFERENCES}

1. American FactFinder. 2009-2013 American Commuinty Survey 5 year Estimates: US Census Bureau; 2011. Available from: https://factfinder census.gov/faces/tableservices/jsf/pages/productview.xhtml? src=bkmk.

2. Pandya Chhandasi MM, Batalova Jeanne,. Limited English Proficient Individuals in the United States: Number, Share, Growth, and Linguistic Diversity. LEP Data Brief. migation Plicy Institute 2011.

3. U.S. Department of Health \& Human Services. Limited English Proficiency (LEP). Office of Civil Rights. Available from: https://www.hhs.gov/civil-rights/ for-individuals/special-topics/limited-english-proficiency/index.html.

4. González CJ, \& Gany, F,. Language Barriers: Loue S, Sajatovic M, eds. Encyclopedia of Immigrant Health. Springer US; 2012.

5. Hampers LC, McNulty, Jennifer E,. Professional Interpreters and Bilingual Physicians in a Pediatric Emergency Department: Effect on Resource Utilization. JAMA Pediatr. 2002;156(11):1108-13.

6. Hu DJ, Covell RM. Health care usage by Hispanic outpatients as function of primary language. Western J Med 1986;144(4):490-3

7. Weinick RM, Krauss NA. Racial/ethnic differences in children's access to care. Am J Public Health 2000;90(11):1771-4.

8. Kirkman-Liff B, Mondragon D. Language of interview: relevance for research of southwest Hispanics. Am J Public Health 1991;81(11):1399-404.

9. Ku L, Flores G. Pay now or pay later: providing interpreter services in health care. Health Affairs (Project Hope) 2005;24(2):435-44.

10. Wilson E, Chen AH, Grumbach $\mathbf{K}$, Wang $\mathbf{F}$, Fernandez A. Effects of limited English proficiency and physician language on health care comprehension. J Gen Intern Med 2005;20(9):800-6.

11. Crane JA. Patient comprehension of doctor-patient communication on discharge from the emergency department. J Emerg Med 1997;15(1):1-7.

12. Fernandez A, Schillinger D, Grumbach $\mathbf{K}$, Rosenthal A, Stewart AL Wang F, et al. Physician language ability and cultural competence. An exploratory study of communication with Spanish-speaking patients. J Gen Intern Med 2004;19(2):167-74.

13. Seijo $\mathbf{R}$, Gomez $\mathbf{H}$, Freidenberg $\mathbf{J}$. Language as a Communication Barrier in Medical Care for Hispanic Patients. Hisp $J$ Behav Sci 2016;13(4):363-76.

14. Weissman JS, Betancourt J, Campbell EG, Park ER, Kim M, Clarridge B, et al. Resident physicians' preparedness to provide cross-cultural care. Jama. 2005;294(9): 1058-67.

15. Diamond L, Grbic D, Genoff M, Gonzalez J, Sharaf R, Mikesell C, et al Non-English-language proficiency of applicants to US residency programs. Jama. 2014;312(22):2405-7.

16. Association of American Medical Colleges. 2015 State Physician Workforce Data Book 2015. Available from: https://www.aamc.org/data/ workforce/reports/442830/statedataandreports.html.

17. Ryan CL, U.S. Census Bureau. Language use in the United States: 2011 in American Community Survey Reports 2013 2013. Available from: https://www.worldcat.org/title/language-use-in-the-united-states2011/oclc/1050334252.

18. Interagency Language Roundtable 2009. Available from: http://www. govtilr.org.

19. Diamond LC, Reuland DS. Describing physician language fluency: deconstructing medical Spanish. Jama. 2009;301(4):426-8.

20. Diamond LC, Luft HS, Chung S, Jacobs EA. "Does this doctor speak my language?" Improving the characterization of physician non-English language skills. Health Serv Res 2012;47(1 Pt 2):556-69.

21. Diamond LC, Tuot DS, Karliner LS. The use of Spanish language skills by physicians and nurses: policy implications for teaching and testing. $J$ Gen Intern Med 2012;27(1):117-23

22. Diamond L, Chung S, Ferguson W, Gonzalez J, Jacobs EA, Gany F. Relationship between self-assessed and tested non-English-language proficiency among primary care providers. Med Care 2014;52(5):435-8.

23. Green AR, Ngo-Metzger Q, Legedza AT, Massagli MP, Phillips RS, Iezzoni LI. Interpreter services, language concordance, and health care quality. Experiences of Asian Americans with limited English proficiency. J Gen Intern Med 2005;20(11):1050-6.

24. Ngo-Metzger $\mathbf{Q}$, Sorkin DH, Phillips RS, Greenfield S, Massagli MP, Clarridge B, et al. Providing high-quality care for limited English proficient patients: the importance of language concordance and interpreter use. J Gen Intern Med 2007;22 Suppl 2:324-30.

25. Manson A. Language Concordance as a Determinant of Patient Compliance and Emergency Room Use in Patients with Asthma Medical Care; 1988.

26. Traylor AH, Schmittdiel JA, Uratsu CS, Mangione CM, Subramanian U. Adherence to cardiovascular disease medications: does patientprovider race/ethnicity and language concordance matter? J Gen Intern Med 2010;25(11):1172-7.

27. Baker DW, Parker RM, Williams MV, Coates WC, Pitkin K. Use and effectiveness of interpreters in an emergency department. Jama. 1996;275(10):783-8.

28. Perez-Stable EJ, Napoles-Springer A, Miramontes JM. The effects of ethnicity and language on medical outcomes of patients with hypertension or diabetes. Med Care 1997;35(12):1212-9.

29. Eamranond PP, Davis RB, Phillips RS, Wee CC. Patient-physician language concordance and lifestyle counseling among Spanish-speaking patients. J Immigr Minor Health 2009; 11(6):494-8.

30. Carter-Pokras O, O'Neill MJ, Cheanvechai V, Menis M, Fan T, Solera A. Providing linguistically appropriate services to persons with limited English proficiency: a needs and resources investigation. Am J Manag Care. 2004;10 Spec No:SP29-36.

31. Jacobs EA, Sadowski LS, Rathouz PJ. The impact of an enhanced interpreter service intervention on hospital costs and patient satisfaction. J Gen Intern Med 2007;22 Suppl 2:306-11.

32. Flores G. The impact of medical interpreter services on the quality of health care: a systematic review. Med Care Res Rev 2005;62(3):255-99.

33. Karliner LS, Jacobs EA, Chen AH, Mutha S. Do professional interpreters improve clinical care for patients with limited English proficiency? A systematic review of the literature. Health Serv Res 2007:42(2):727-54.

34. Burbano O'Leary SC, Federico S, Hampers LC. The truth about language barriers: one residency program's experience. Pediatrics. 2003;111(5 Pt 1):e569-73.

35. Diamond LC, Schenker Y, Curry L, Bradley EH, Fernandez A. Getting by: underuse of interpreters by resident physicians. J Gen Intern Med 2009;24(2):256-62

36. Schenker Y, Wang F, Selig SJ, Ng R, Fernandez A. The impact of language barriers on documentation of informed consent at a hospital with on-site interpreter services. J Gen Intern Med 2007;22 Suppl 2:2949.

37. Yawman D, McIntosh S, Fernandez D, Auinger P, Allan M, Weitzman M. The use of Spanish by medical students and residents at one university hospital. Acad Med 2006;81(5):468-73.

38. U.S. Department of Health and Human Services Office of Minority Health. National Standards for Culturaly and Linguistically Appropriate Services (CLAS) 2013. Available from: https://minorityhealth.hhs.gov/Default.aspx.

39. Lee KC, Winickoff JP, Kim MK, Campbell EG, Betancourt JR, Park ER, et al. Resident physicians' use of professional and nonprofessional interpreters: a national survey. Jama. 2006;296(9):1050-3.

40. Rodriguez F, Cohen A, Betancourt JR, Green AR. Evaluation of medical student self-rated preparedness to care for limited English proficiency patients. BMC Med Educ 2011;11:26.

41. Cardinal LJ, Maldonado M, Fried ED. A National Survey to Evaluate Graduate Medical Education in Disparities and Limited English Proficiency: A Report From the AAIM Diversity and Inclusion Committee. Am J Med 2016;129(1):117-25.

42. Xierali IM, Castillo-Page L, Conrad S, Nivet MA. Analyzing Physician Workforce Racial and Ethnic Composition Associations: Geographic Distribution (Part II) (Volume 14, Number 9) 2014. Available from: https://www.aamc.org/download/401814/data/. 
43. Association of American Medical Colleges. Optimizing Graduate Medical Education: A Five-Year Road Map for America's Medical Schools, Teaching Hospitals and Health Systems 2015. Available from: https://www.aamc.org/download/425468/data/ optimizinggmereport.pdf.

44. Grumbach $\mathbf{K}$, Mendoza $\mathbf{R}$. Disparities in human resources: addressing the lack of diversity in the health professions. Health Affairs (Project Hope) 2008;27(2):413-22.

45. Walker KO, Moreno G, Grumbach K. The association among specialty, race, ethnicity, and practice location among California physicians in diverse specialties. J Natl Med Assoc 2012;104(1-2):46-52.
46. Hughes S, Zweifler J, Schafer S, Smith MA, Athwal S, Blossom HJ. High school census tract information predicts practice in rural and minority communities. J Rural Health 2005;21(3):228-32.

47. Rabinowitz HK, Diamond JJ, Markham FW, Hazelwood CE. A program to increase the number of family physicians in rural and underserved areas: impact after 22 years. Jama. 1999;281(3):255-60.

48. Grow RW, Sztajnkrycer MD, Moore BR. Language barriers as a reported cause of prehospital care delay in Minnesota. Prehospital Emergency Care 2008; 12(1):76-9

Publisher's Note: Springer Nature remains neutral with regard to jurisdictional claims in published maps and institutional affiliations. 